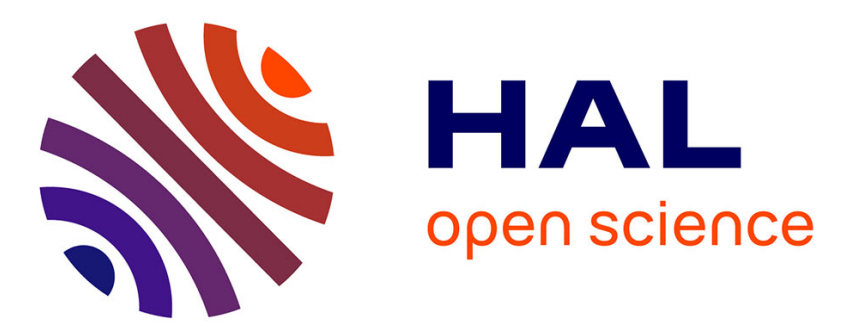

\title{
Influence of Angles of Attack, Frequency and Kick Amplitude on Swimmer's Horizontal Velocity During Underwater Phase of a Grab Start
}

\author{
Nicolas Houel, Marc Elipot, Frédéric André, Philippe Hellard
}

\section{To cite this version:}

Nicolas Houel, Marc Elipot, Frédéric André, Philippe Hellard. Influence of Angles of Attack, Frequency and Kick Amplitude on Swimmer's Horizontal Velocity During Underwater Phase of a Grab Start. Journal of Applied Biomechanics, 2013, 29 (1), pp.49-54. 10.1123/jab.29.1.49 . hal-01839029

\section{HAL Id: hal-01839029 \\ https: / hal-insep.archives-ouvertes.fr/hal-01839029}

Submitted on 23 Jul 2018

HAL is a multi-disciplinary open access archive for the deposit and dissemination of scientific research documents, whether they are published or not. The documents may come from teaching and research institutions in France or abroad, or from public or private research centers.
L'archive ouverte pluridisciplinaire HAL, est destinée au dépôt et à la diffusion de documents scientifiques de niveau recherche, publiés ou non, émanant des établissements d'enseignement et de recherche français ou étrangers, des laboratoires publics ou privés. 


\title{
Influence of Angles of Attack, Frequency and Kick Amplitude on Swimmer's Horizontal Velocity During Underwater Phase of a Grab Start
}

\author{
Nicolas Houel, Marc Elipot, Frédéric André, and Philippe Hellard \\ Pôle Natation, INSEP
}

\begin{abstract}
The underwater phase of starts represents an important part of the performance in sprint swimming's events. Kinematics variables that swimmers have to take into account to improve their underwater phase of starts are unknown. The aim of this study was to determine the kinematics variables that improve performance during the underwater phase of grab starts. A three-dimensional analysis of the underwater phase of ten swimmers of national level was conducted. Stepwise multiple linear regressions identified the main kinematics variables that influence the horizontal velocity of the swimmer each $0.5 \mathrm{~m}$ in the range of 5 to $7.5 \mathrm{~m}$. The results show that the kinematics parameters change during the range of 5 to $7.5 \mathrm{~m}$ of the underwater phase of the starts. For this population of swimmers, the results enable proposals of four principles to improve the underwater phase: i) to be streamlined at the beginning of the underwater gliding phase, ii) to start the dolphin kicking after $6 \mathrm{~m}$, iii) to generate propulsive forces using only feet and legs during underwater undulatory swimming, iv) to improve the frequency of underwater undulatory swimming.
\end{abstract}

Keywords: swimming starts, kinematics, undulations, performance

In 50 and $100 \mathrm{~m}$ swimming races, performance has been strongly linked to starts performance (Arellano et al., 1996; Mason \& Cossor, 2000). Starts performance is defined as the time observed between the start signal and the moment when the swimmer's head reaches 10 m (Arellano et al., 1996) or 15 m (Issurin \& Verbitsky, 2002; Mason \& Cossor, 2000).

Swimmers currently use the grab start or the track start in national and international events. In the grab start, swimmer places both feet at the front of the block and hands grabbing the front edge of the block. In the track start, with the same hand placement, swimmer places one foot at the front edge of the block, the other foot is back on the starting block (Holthe \& McLean, 2001; Welcher et al., 2008).

The start is defined as a sequence of three phases: the impulse phase on the starting block (including reaction time), the flight phase, and the underwater phase. The results of studies conducted since the 1970's defining the most effective start remain contradictory (Issurin \& Verbitsky, 2002; Vilas-Boas et al., 2003). However, there is some agreement that horizontal and vertical velocities, as well as minimized hydrodynamic resistance when

Nicolas Houel (Corresponding Author), Marc Elipot, Frédéric André, and Philippe Hellard are with the Département Recherche Fédération Française de Natation, Pôle Natation, INSEP, Paris, France. entering in the water have direct impact on the underwater phase (Holthe \& McLean, 2001; Miller et al., 2002; Elipot et al., 2009).

The underwater phase is described as gliding phase with underwater leg propulsion (Elipot et al., 2009). When entering the water, swimmer's velocity (around $3.61 \mathrm{~m} \cdot \mathrm{s}^{-1}$ ) is greater than the one that can be produced by underwater propulsion (Elipot et al., 2009). During the gliding phase, the streamline position (Marinho et al., 2009) directly influences the hydrodynamic resistance. Swimmer propulsive movements should ideally be initiated when the underwater velocity reaches between 2.2 and $1.9 \mathrm{~m} \cdot \mathrm{s}^{-1}$ (Lyttle et al., 2000). Based on this result, Elipot et al. (2009) showed that the optimal beginning of the propulsive movement appeared when the swimmer center of mass reached 5.61-6.01 $\mathrm{m}$ from the wall start. In this situation, underwater propulsion becomes more critical. The underwater leg propulsion phase is currently called "underwater undulatory swimming" (Arellano et al., 2003; von Loebbecke et al., 2009).

The underwater undulatory swimming of fish and human locomotion has been studied using an oscillating foil (Anderson et al., 1998). These studies showed that the oscillation of the foils created a vortex wake associated with drag or thrust (Anderson et al., 1998). Under specific conditions, an oscillating foil can modify the von Karman street of the wake and generate propulsive force or lift for maneuvering (Anderson et al., 1998). These specific conditions are defined by the Reynolds number, the angle 
of attack ( $\alpha$ ) and the Strouhal number (Anderson et al., 1998). The Reynolds number is a dimensionless number which divides forward speed $(U)$ and characteristic length of the swimmer by kinematic viscosity. The Reynolds number represents the nature (laminar to turbulent) of the flow circulation around the body. The angle of attack is the angle between the flow velocity and the chord of the body. The angle of attack influences directly the drag and lift coefficient (Rouboa et al., 2006). The Strouhal number is a dimensionless number which divides strokes frequency $(f)$ and amplitude $(A)$ by forward speed (Taylor et al., 2003). The Strouhal number represents the ratio of unsteady and steady motion. The Strouhal number is an important factor in determining propulsion forces and swimming efficiency (Anderson et al., 1998). Taylor et al. (2003) clearly defined the relation between the Strouhal number, the angle of attack and the aerodynamic or hydrodynamic coefficient which depends of the Reynolds number Re. For them: "The Strouhal number is bound to affect the hydrodynamic force coefficients and propulsive efficiency, because it defines the maximum angle of attack associated with modifications of vortices, which are the source of hydrodynamic force production" (Taylor et al., 2003).

All these specific conditions can't be easily estimated during the start underwater phase because of the velocity decrease of the swimmer, as well as the modification of the swimmers' segment orientation and coordination. But some of these $(U, \alpha, A, f)$ can be described and studied during each part of the underwater phase. From what we know, each of the independent phases of gliding and underwater leg propulsion have been clearly investigated. But few researches clearly focus on the swimmers' strategy to optimize speed during the underwater phase of the start. The main goals of this research are: i) to estimate the velocity of the swimmer's center of mass and hip during the underwater phase of grab start and ii) to define the determinant factors in this underwater phase related to performance.

\section{Method}

The experiment took place at the INSEP swimming pool (French National Institute of Sport, INSEP, France). Ten volunteers' swimmers of national level (mean $\pm S D$ : age $=21.41 \pm 4.54$ years; height $=183.33 \pm 4.88 \mathrm{~cm}$; mass $=75.8 \pm 5.09 \mathrm{~kg}$ ) participated in the study. All were informed of the objectives and signed a consent form. All swimmers practiced grab start and underwater undulatory swimming on a regular basis and used them for competitive racing. For the purpose of the study, they were asked to perform a competitive grab start as efficiently as possible.

The underwater area between the wall $(0 \mathrm{~m})$ to $10 \mathrm{~m}$ was recorded using three camcorders (Panasonic NV-GS17 and Sony DCR-HC20E). Two camcorders (camera 1, 2) were fixed behind windows (Figure 1). These camcorders recorded a sagittal view of the swimmers' trajectories. The third camcorder was placed in a waterproof case (Sony HCG Sports pack waterproof case). This third video camera recorded a slanting view of the swimmer motion. The angles between the principal axis of camera 3 and the other cameras were between $60^{\circ}$ and $70^{\circ}$. The underwater area was divided into two zones measuring $5 \times 2 \times 2 \mathrm{~m}$ (length, width, weight): The first zone was from the start wall to the 5 $\mathrm{m}$ distance. The second zone was from the $5 \mathrm{~m}$ to the $10 \mathrm{~m}$ distance. Each zone was recorded by two cameras. Cameras 1 and 3 recorded the first zone. Camera 2 and 3 recorded the second zone (Figure 1). To limit the effect of the image distortions (due to camera lens deformation) on reconstruction accuracy, only the points contained in the $2 / 3$ center of the camera field have been reconstructed. To improve the reconstruction accuracy, the cameras were positioned to minimize optical refraction effects (Snell's law), the long distance between the cameras and the center of each zone (Kwon, 1999) and the camcorders' optical axes were perpendicular to the air-water interface plane. Cameras were synchronized with a light flash. The sampling frequency was $25 \mathrm{~Hz}$. The video was interlaced scan and the both odd and even fields were used. The gliding and underwater undulatory swimming phase was recorded from the instant when the swimmers were completely under water until the instant they began arm propulsion. To minimize errors during the digitizing process, the two sides of the swimmer's body were assumed to be symmetric. Only the right side was digitized. Nine anatomical landmarks were identified on the swimmers with Simimotion software: the toe, the lateral malleolus, the knee, the iliac spine, the acromion, a finger tip, the wrist, the elbow, and the center of the head. A modified double plane direct linear transformation method (inspired by Drenk et al., 1999) was used to calculate the landmark coordinates in space. Space mean reconstruction accuracy, calculated as described by Kwon and Casebolt (2006), was $6.2 \mathrm{~mm}$. Data were filtered with a second-order Butterworth filter (Winter, 1990). Cut-off frequencies were between 5 and $7 \mathrm{~Hz}$. The landmark's positions associated with Dempster's anthropometric data (1959) were used to determine the trajectory of the center of mass. Using the coordinates of the landmarks and the center of mass, the following variables were defined.

- The horizontal velocity of the center of mass $\left(\mathrm{Vx}_{\mathrm{g}}\right)$ and hip $\left(\mathrm{Vx}_{\mathrm{h}}\right)$

- The angle of attack of segments trunk $\left(\alpha_{\text {tr }}\right)$, thigh $\left(\alpha_{\mathrm{th}}\right)$, leg $\left(\alpha_{\mathrm{le}}\right)$, foot $\left(\alpha_{\mathrm{fo}}\right)$ which were defined as the angle between each segment and the velocity vector of this proximal landmarks

- The mean kick frequency $(f)$ of the underwater undulatory swimming or the reverse period of the ankle motion

- The mean kick amplitude (A) or the mean peak to peak amplitude of the ankle during the underwater undulatory swimming. 


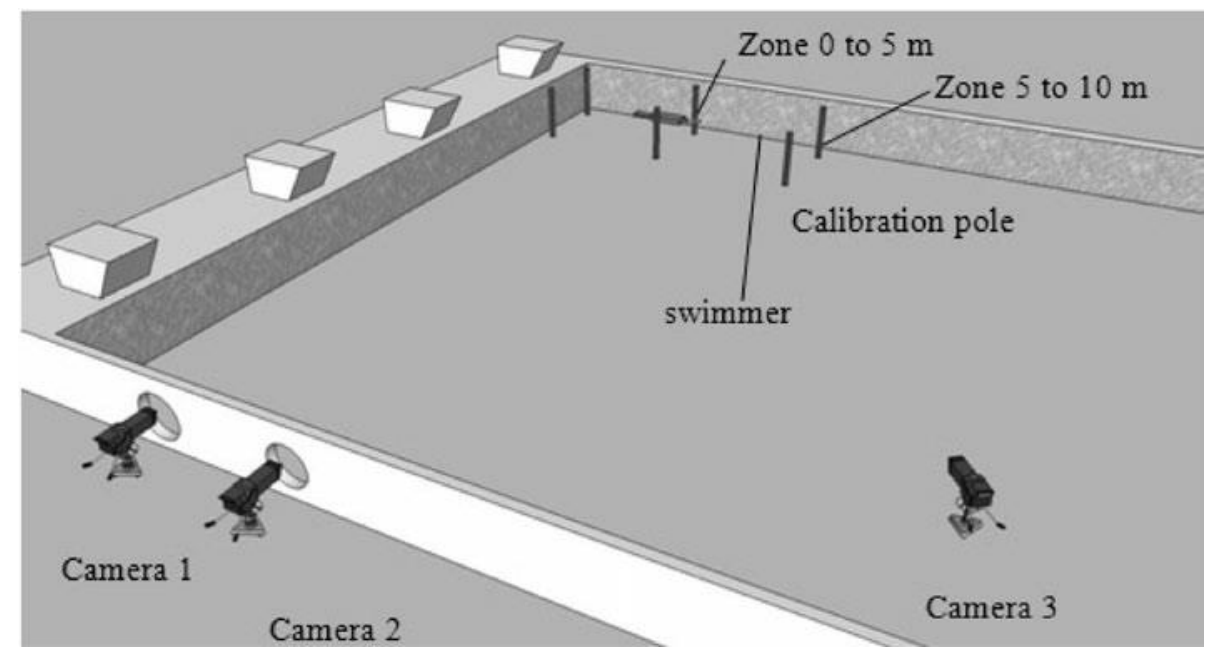

Figure 1 - Experimental setup.

These variables were calculated for each swimmer every $0.5 \mathrm{~m}$ between $5 \mathrm{~m}$ to $7.5 \mathrm{~m}$. After $7.5 \mathrm{~m}, 30 \%$ (three swimmers) of the total number of swimmers began arm propulsion. For the range of distance, the normality of the variables was tested using Lilliefors test (Lilliefors, 1967). Mean frequency, kick amplitude and velocity of the swimmer's center of mass and hip were calculated at each normalized distance. The effect of the independent variables $\left(\alpha_{\mathrm{tr}}, \alpha_{\mathrm{th}}, \alpha_{\mathrm{le}}, \alpha_{\mathrm{fo}}, \mathrm{f}, \mathrm{A}\right)$ on the dependent variables $\mathrm{Vx}_{\mathrm{g}}$ and $\mathrm{Vx}_{\mathrm{h}}$ at each normalized distance was analyzed using multiple stepwise linear regression. Correlation between independent variables $\left(\alpha_{\mathrm{tr}}, \alpha_{\mathrm{th}}, \alpha_{\mathrm{le}}, \alpha_{\mathrm{fo}}, \mathrm{f}, \mathrm{A}\right)$ and dependant variables $\mathrm{Vx}_{\mathrm{g}}$ and $\mathrm{Vx}_{\mathrm{h}}$ at each normalized distance were determined. The limit of significance was set as $p \leq .05$.

\section{Results}

Mean velocity of the swimmer's center of mass and hip decreased during the underwater undulatory swimming phase of a grab start (Figure 2). Multiple stepwise linear regression (Table 1 and 2) and correlation (Table 3 and 4) analysis showed that different independent variables $\left(\alpha_{\mathrm{tr}}, \alpha_{\mathrm{th}}, \alpha_{\mathrm{le}}, \alpha_{\mathrm{fo}}, \mathrm{f}, \mathrm{A}\right)$ were ranked as best predictors of the underwater horizontal velocity $\mathrm{Vx}_{\mathrm{g}}$ and $\mathrm{Vx}_{\mathrm{h}}$, at each distance between 5.5 and $7.5 \mathrm{~m}$. These independent variables had different effect on the center of mass $\left(\mathrm{Vx}_{\mathrm{g}}\right)$ and the hip velocities $\left(\mathrm{Vx}_{\mathrm{h}}\right)$. At $5 \mathrm{~m}$, mean velocities were $\mathrm{Vx}_{\mathrm{g}}=2.46 \pm 0.17 \mathrm{~m} \cdot \mathrm{s}^{-1}$ and $\mathrm{Vx}_{\mathrm{h}}=2.59 \pm 0.21 \mathrm{~m} \cdot \mathrm{s}^{-1}$. No significant result was found at $5 \mathrm{~m}$. At $5.5 \mathrm{~m}$, mean velocities were $\mathrm{Vx}_{\mathrm{g}}=2.18 \pm 0.2 \mathrm{~m} \cdot \mathrm{s}^{-1}$ and $\mathrm{Vx}_{\mathrm{h}}=2.14 \pm$ $0.26 \mathrm{~m} \cdot \mathrm{s}^{-1}$. Multiple stepwise regression analysis showed that the angle of attack of the trunk $\left(\alpha_{\mathrm{tr}}\right)$ and amplitude (A) were the variables that present better $\operatorname{Vx}_{\mathrm{g}}\left(R^{2}=.44\right.$; $p=.036)$ and $\mathrm{Vx}_{\mathrm{h}}\left(R^{2}=.57 ; p=.0012\right)$. At this distance, $\mathrm{Vx}_{\mathrm{g}}$ was significantly correlated with $\alpha_{\mathrm{tr}}(r=-0.64, p=$ $.042), \mathrm{A}(r=-0.66, p=.036)$ and $\alpha_{\mathrm{le}}(r=-0.63, p=.049)$. $\mathrm{Vx}_{\mathrm{h}}$ was significantly correlated with $\alpha_{\mathrm{tr}}(r=-0.75, p=$ $.012), \mathrm{A}(r=-0.69, p=.026), \alpha_{\mathrm{le}}(r=-0.73, p=.016)$ and $\alpha_{\mathrm{th}}(r=-0.63, p=.046)$. At $6 \mathrm{~m}$, mean velocities were $\mathrm{Vx}_{\mathrm{g}}=1.99 \pm 0.13 \mathrm{~m} \cdot \mathrm{s}^{-1}$ and $\mathrm{Vx}_{\mathrm{h}}=2.05 \pm 0.11$ $\mathrm{m} \cdot \mathrm{s}^{-1}$. Multiple stepwise regression analysis showed that

Table 1 Regression equation with statistical coefficient $\left(R^{2}\right)$ and $P$ values of independent variables which present the horizontal velocity of the center of mass $\left(\mathbf{V x}_{\mathrm{g}}\right)$

\begin{tabular}{llcc}
\hline Distance $(\mathrm{m})$ & Equation & $\begin{array}{c}\text { Correlation } \\
\text { Coefficient, } \boldsymbol{R}^{2}\end{array}$ & $\boldsymbol{P}$ value \\
\hline 5 & - & - & - \\
5.5 & $\mathrm{Vx}_{\mathrm{g}}=-0.03 \mathrm{~A}$ & $R^{2}=.438$ & $P=0.036$ \\
6 & $\mathrm{Vx}_{\mathrm{g}}=-0.06 \alpha_{\mathrm{fo}}$ & $R^{2}=.428$ & $P=0.040$ \\
6.5 & $\mathrm{Vx}_{\mathrm{g}}=-0.01 \alpha_{\mathrm{th}}+0.004 \alpha_{\mathrm{le}}+0.33 f$ & $R^{2}=.862$ & $P=0.005$ \\
7 & $\mathrm{Vx}_{\mathrm{g}}=0.81 f$ & $R^{2}=.455$ & $P=0.032$ \\
\hline 7.5 & - & - & - \\
\hline
\end{tabular}


Table 2 Regression equation with statistical coefficient and $P$ values of independent variables which present the horizontal velocity of the hip $\left(V_{h}\right)$

\begin{tabular}{llcc}
\hline Distance $(\mathrm{m})$ & Equation & $\begin{array}{c}\text { Correlation } \\
\text { Coefficient, } \boldsymbol{R}^{2}\end{array}$ & P value \\
\hline 5 & - & - & - \\
5.5 & $\mathrm{Vx}_{\mathrm{h}}=-0.02 \alpha_{\mathrm{tr}}$ & $R^{2}=.566$ & $P=0.012$ \\
6 & - & - & - \\
6.5 & $\mathrm{Vx}_{\mathrm{h}}=-0.02 \alpha_{\mathrm{th}}+0.4 f$ & $R^{2}=.884$ & $P=0.0005$ \\
7 & $\mathrm{Vx}_{\mathrm{h}}=-0.02 \alpha_{\mathrm{tr}}$ & $R^{2}=.534$ & $P=0.016$ \\
\hline 7.5 & $\mathrm{Vx}_{\mathrm{h}}=0.62 f$ & $R^{2}=.683$ & $P=0.011$ \\
\hline
\end{tabular}

Table 3 Significant correlation between kinetic parameters and the horizontal velocity of the center of mass $\left(\mathbf{V x}_{\mathrm{g}}\right)$

\begin{tabular}{lcc}
\hline Kinetic Parameters & r value & P value \\
\hline Angle of attack of trunk $\left(\alpha_{\mathrm{tr}}\right)$ at $5.5 \mathrm{~m}$ & -0.648 & 0.042 \\
Amplitude $(\mathrm{A})$ at $5.5 \mathrm{~m}$ & -0.662 & 0.036 \\
Angle of attack of leg $\left(\alpha_{\mathrm{le}}\right)$ at $5.5 \mathrm{~m}$ & -0.632 & 0.049 \\
Angle of attack of foot $\left(\alpha_{\mathrm{fo}}\right)$ at $6 \mathrm{~m}$ & -0.654 & 0.040 \\
Angle of attack of thigh $\left(\alpha_{\mathrm{th}}\right)$ at $6.5 \mathrm{~m}$ & -0.648 & 0.042 \\
Frequency $(f)$ at $7 \mathrm{~m}$ & 0.674 & 0.032 \\
\hline
\end{tabular}

Table 4 Significant correlation between kinetic parameters and the horizontal velocity of the hip $\left(\mathrm{Vx}_{\mathrm{h}}\right)$

\begin{tabular}{lcc}
\hline Kinetic Parameters & rvalue & $\boldsymbol{P}$ value \\
\hline Angle of attack of trunk $\left(\alpha_{\mathrm{tr}}\right)$ at $5.5 \mathrm{~m}$ & -0.752 & 0.012 \\
Amplitude $(\mathrm{A})$ at $5.5 \mathrm{~m}$ & -0.691 & 0.026 \\
Angle of attack of leg $\left(\alpha_{\mathrm{le}}\right)$ at $5.5 \mathrm{~m}$ & -0.731 & 0.016 \\
Angle of attack of thigh $\left(\alpha_{\mathrm{th}}\right)$ at $5.5 \mathrm{~m}$ & -0.638 & 0.046 \\
Angle of attack of thigh $\left(\alpha_{\mathrm{th}}\right)$ at $6.5 \mathrm{~m}$ & -0.837 & 0.002 \\
Angle of attack of trunk $\left(\alpha_{\mathrm{tr}}\right)$ at $7 \mathrm{~m}$ & -0.731 & 0.016 \\
Frequency $(f)$ at $7.5 \mathrm{~m}$ & 0.826 & 0.011 \\
Angle of attack of trunk $\left(\alpha_{\mathrm{tr}}\right)$ at $7.5 \mathrm{~m}$ & -0.738 & 0.036 \\
\hline
\end{tabular}

the angle of attack of the foot $\left(\alpha_{\mathrm{fo}}\right)$ was the variable that present better $\mathrm{Vx}_{\mathrm{g}}\left(R^{2}=.43 ; p=.04\right)$. At this distance, $\mathrm{Vx}_{\mathrm{g}}$ was only significantly correlated with $\alpha_{\mathrm{fo}}(r=-0.65$, $p=.040)$. At $6.5 \mathrm{~m}$, mean velocities were $\mathrm{Vx}_{\mathrm{g}}=1.93 \pm$ $0.14 \mathrm{~m} \cdot \mathrm{s}^{-1}$ and $\mathrm{Vx}_{\mathrm{h}}=1.9 \pm 0.19 \mathrm{~m} \cdot \mathrm{s}^{-1}$. Multiple stepwise regression analysis showed that the angle of attack of the thigh $\left(\alpha_{\mathrm{th}}\right)$, the angle of attack of the leg $\left(\alpha_{\mathrm{le}}\right)$ and the frequency $(f)$ were the best predictors of $\mathrm{Vx}_{\mathrm{g}}\left(R^{2}=.86\right.$, $p=.005)$. The angle of attack of the thigh $\left(\alpha_{\mathrm{th}}\right)$ and the frequency $(f)$ were the best predictors of $\mathrm{Vx}_{\mathrm{h}}\left(R^{2}=.88\right.$, $p=.0005)$. At this distance, $\mathrm{Vx}_{\mathrm{g}}$ was only significantly correlated to $\alpha_{\text {th }}(r=-0.64, p=.042)$. $\mathrm{Vx}_{\mathrm{h}}$ was only significantly correlated to $\alpha_{\mathrm{th}}(r=-0.83, p=.002)$. At $7 \mathrm{~m}$, mean velocities were $\mathrm{Vx}_{\mathrm{g}}=1.74 \pm 0.25 \mathrm{~m} \cdot \mathrm{s}^{-1}$ and
$\mathrm{Vx}_{\mathrm{h}}=1.73 \pm 0.24 \mathrm{~m} \cdot \mathrm{s}^{-1}$. Multiple stepwise regression analysis showed that the frequency $(f)$ was the variable that presents better $\mathrm{Vx}_{\mathrm{g}}\left(R^{2}=.45, p=.032\right)$. The angle of attack of the trunk $\left(\alpha_{\mathrm{tr}},\right)$ was the variable that presents better $\mathrm{Vx}_{\mathrm{h}}\left(R^{2}=.53, p=.016\right)$. $\mathrm{Vx}_{\mathrm{g}}$ was significantly correlated to $f(r=.67, p=.032)$. $\mathrm{Vx}_{\mathrm{h}}$ was significantly correlated to $\alpha_{\text {tr }}(r=-0.73, p=.036)$. At $7.5 \mathrm{~m}$, mean velocities were $\mathrm{Vx}_{\mathrm{g}}=1.76 \pm 0.17 \mathrm{~m} \cdot \mathrm{s}^{-1}$ and $\mathrm{Vx}_{\mathrm{h}}=1.81 \pm$ $0.17 \mathrm{~m} \cdot \mathrm{s}^{-1}$. Mean kick frequency were $f=2.32 \pm 0.22 \mathrm{~Hz}$ and mean amplitude were $A=70.8 \pm 6.04 \mathrm{~cm}$. Multiple stepwise regression analysis showed that the frequency $(f)$ was the variable that presents better $\operatorname{Vx}_{\mathrm{h}}\left(R^{2}=.68\right.$, $p=.011)$. $\mathrm{Vx}_{\mathrm{h}}$ was significantly correlated to $f(r=.82$, $p=.011)$ and $\alpha_{\mathrm{tr}}(r=-0.73, p=.036)$. 


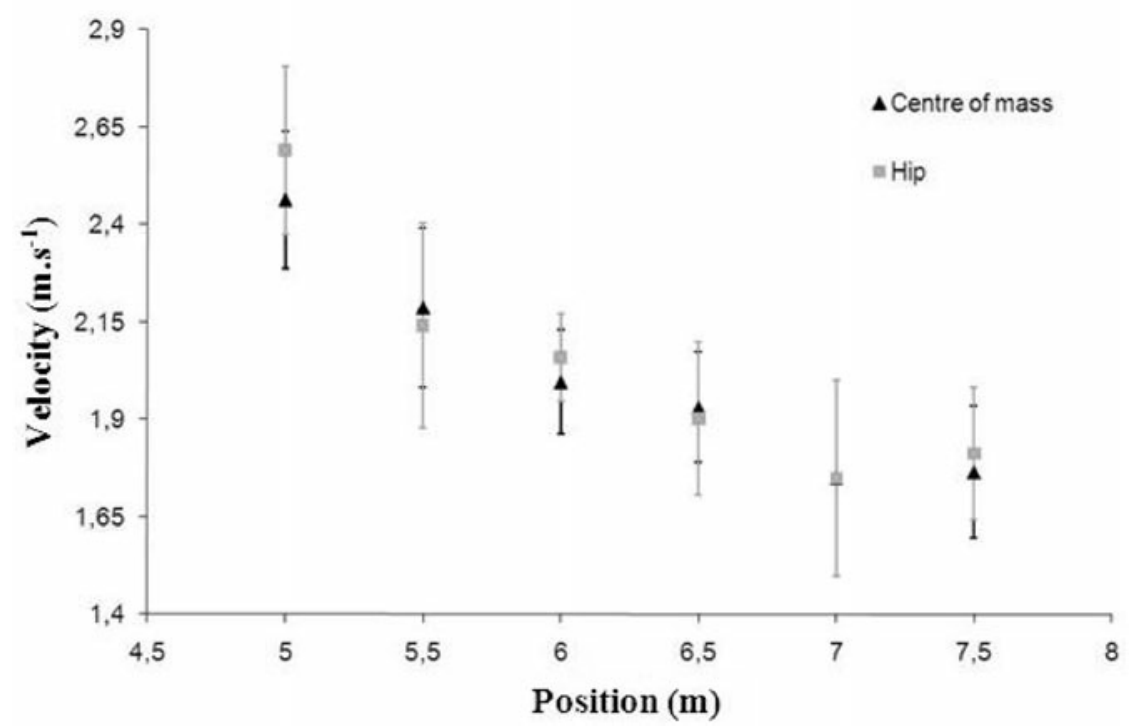

Figure 2 - Variation of the mean velocity center of mass $\left(\mathrm{Vx}_{\mathrm{g}}\right)$ and hip $\left(\mathrm{Vx}_{\mathrm{h}}\right)$ with standard deviation.

\section{Discussion}

This study showed that mean velocity of the swimmer decreases during the underwater phase of a grab start. In this situation, different kinematics variables should be used by the swimmer who wants to limit the loss of his center of mass and hip horizontal velocities during underwater undulatory swimming. These kinematics variables are different at each distance of the underwater undulatory swimming.

The most important limitation of the results using multiple stepwise linear regression analysis is the low number (n) of subjects to predict independent variables (k) using stepwise regression (Fonton \& Palm, 1998). In our present study: $n<3 \times \mathrm{k}$ and $\mathrm{k}<\mathrm{n}$. For $R^{2}>.4$, the multiple stepwise regression analysis can only select the independent variables that present better the dependant variables. For $R^{2}>.8$, the multiple stepwise regression analysis presents the independent variables as best predictors and explains more than $50 \%$ of the event variability (Fonton \& Palm, 1998). The regression results were based on the specific way that independent variables were entered on the regression equation.

This study showed that the horizontal velocity of the center of mass and the hip during underwater undulatory swimming were explained by different kinematics variables. This is in agreement with results observed in intracycle swimming where the hip motion can't be used as center of mass indicator to explain the swimmer's motion (Barbosa et al., 2003; Psycharakis \& Sanders, 2009). In the case of our present study, multiple stepwise regression analysis realized on the center of mass and the hip velocities helped to understand the swimmer's motion and how to optimize his underwater undulatory swimming.

The results of the current study indicated that the swimmer should stay in a streamlined position and limit the underwater undulatory swimming before he reaches $6 \mathrm{~m}$. At this distance, mean velocities were $\mathrm{Vx}_{\mathrm{g}}=1.99$ $\pm 0.13 \mathrm{~m} \cdot \mathrm{s}^{-1}$ and $\mathrm{Vx}_{\mathrm{h}}=2.05 \pm 0.11 \mathrm{~m} \cdot \mathrm{s}^{-1}$. These results are in agreement with the previous works (Lyttle et al., 2000; Elipot et al., 2009). In case the swimmer would have begun its underwater undulatory swimming too early, hydrodynamic resistances would have increased and limited the performance of the underwater phase of the start (Elipot et al., 2009). The decrease of the angle of attack of the trunk $\left(\alpha_{\mathrm{tr}}\right)$ and the foot $\left(\alpha_{\mathrm{fo}}\right)$ as selected variable to improve $\mathrm{Vx}_{\mathrm{g}}$ and $\mathrm{Vx}_{\mathrm{h}}$, confirmed that the angles of attack directly influence drag and lift coefficients of the body (Rouboa et al., 2006; Naemi et al., 2010).

Decreasing the angle of attack of the thigh $\left(\alpha_{\mathrm{th}}\right)$ at $6.5 \mathrm{~m}$ associated with increasing the angle of attack of the leg $\left(\alpha_{\mathrm{le}}\right)$ and increasing the frequency $(f)$ have improved the horizontal velocities $\mathrm{Vx}_{\mathrm{g}}$ and $\mathrm{Vx}_{\mathrm{h}}$. So angles of attack of the human segments have different impacts on the swimming propulsion efficiency. This result is in agreement with studies realized on fish (von Loebbecke et al., 2009). As like for dolphins, the human underwater undulatory swimming tends to minimize the displacement of the drag produced by the forward parts of the body, and to maximize the displacement of the thrust produced by the legs and the feet. The displacement wave that travels the length of the body also has a small magnitude along the torso, and reaches a maximum at the toes.

At $7.5 \mathrm{~m}$, the mean velocities of the swimmers $\left(\mathrm{Vx}_{\mathrm{g}}\right.$ $\left.=1.76 \pm 0.17 \mathrm{~m} \cdot \mathrm{s}^{-1} ; \mathrm{Vx}_{\mathrm{h}}=1.81 \pm 0.17 \mathrm{~m} \cdot \mathrm{s}^{-1}\right)$, mean kick frequency $(f=2.32 \pm 0.22 \mathrm{~Hz})$ and mean amplitude (A $=70.8 \pm 6.04 \mathrm{~cm}$ ) were higher than the results observed in the study of Gavilan et al. (2006) and von Loebbecke et al. (2009). The result of the multiple stepwise regression analysis and the comparison with the results of the previous studies (Gavilan et al., 2006; von Loebbecke et al., 2009) confirms that the swimmer can improve his 
velocity by increasing kick frequency and maintaining large kick amplitude.

\section{Conclusion}

This study tends to suggest that the swimmer should apply three principles to improve his underwater start phase: i) to be streamlined with linear adjustment of the trunk and the lower body segments at the beginning of the underwater gliding phase, ii) to start the underwater undulatory swimming after $6 \mathrm{~m}$, iii) to generate propulsive kicking using only feet and legs during underwater undulatory swimming, iv) to improve the kick frequency of underwater undulatory swimming.

\section{Acknowledgments}

The authors wish to thank the "Ministère des Sports" and the "Fédération Française de Natation" for financing this study. The authors also wish to thank Frédéric Frontier, Frédéric Clerc, Isabelle Amaudry and the "INSEP" for logistic support, and Jean-Lyonel Rey, Stéphane Lecat, Eric Boissière and Yves Thomassin for their contributions.

\section{References}

Anderson, J.M., Streitlien, K., Barret, D.S., \& Triantafyllou, M.S. (1998). Oscillating foils of high propulsive effi y. Journal of Fluid Mechanics, 360, 41-72. doi:10.1017/ S0022112097008392

Arellano, R., Moreno, F.J., Martinez, M., \& Ona, A. (1996). A device for quantitative measurement of starting time in swimming. Biomechanics and Medicine in swimming VII, 195-200. London: E \& FN Spon.

Arellano, R., Pardillo, S., \& Gavilan, A. (2003). Usefulness of the strouhal number in evaluating human underwater undulatory swimming. Biomechanics and Medicine in Swimming IX. University of Saint-Etienne, France, 33-38.

Barbosa, T., Santos Silva, J.V., Sousa, F., \& Vilas-Boas, J.P. (2003). Comparative study of the reponse of kinemtical variables from the hip and the center of mass in butterfliers. Biomechanics and Medicine in Swimming IX. University of Saint-Etienne, France, 83-98.

Drenk, V., Hildebrand, F., Kindler, M., \& Kliche, D. (1999). A 3D video technique for analysis of swimming in a flume. Scientific Proceeding of the XVII International Symposium on Biomechanics in Sport, Perth, Australia, 361-364.

Elipot, M., Hellard, P., Taiar, R., Boissière, E., Rey, J.L., Lecat, S., \& Houel, N. (2009). Analysis of swimmers velocity during the underwater gliding motion following grab start. Journal of Biomechanics, 42, 1367-1370. PubMed doi:10.1016/j.jbiomech.2009.03.032

Fonton, N.H., \& Palm, R. (1998). Comparaison empirique de methods de prediction en regression lineaire multiple. Revue de Statistique Appliquee, 96, 53-64.

Holthe, M.J., \& McLean, S.P. (2001). Kinematic comparison of grab and track starts in swimming. International Sympo-

sium on Biomechanics in Sports, 19. John R. Blackwell and Ross

H. Sanders (Eds.) Biomechanics Symposia, 31-34. Issurin,

V.B., \& Verbitsky, O. (2002). Track start versus Grab Start: Evidence of the Sydney Olympic Games. Biomechanics and Medicine in Swimming IX, University of Saint-Etienne, France, 213-218.
Gavilan, A., Arellano, R.. \& Sanders, R. (2006). Underwater undulatory swimming: study of frequency, amplitude and phase characteristics of the "body wave." Biomechanics and Medicine in Swimming X, Portuguese Journal of Sport Sciences, 35-37.

Kwon, Y.H. (1999). Object plane deformation due to refraction in two dimensional underwater motion analysis. Journal of Applied Biomechanics, 15, 396-403.

Kwon, Y.H., \& Casebolt, J.B. (2006). Effects of light refraction on accuracy of camera calibration and reconstruction in underwater motion analysis. Sports Biomechanics, 5, 95-120. PubMed doi:10.1080/14763141.2006.9628227

Lilliefors, H.W. (1967). On the Kolmogorov-Smirnov test for normality with mean and variance unknown. Journal of the American Statistical Association, 62, 399-402. doi:1 0.1080/01621459.1967.10482916

Lyttle, A.D., Blanksby, B.A., Elliot, B.C., \& Lloyd, D.G. (2000). Bet forces during tethered simulation of underwater streamlined gliding and kicking techniques of freestyle turn. Journal of Sports Sciences, 18, 801-807. PubMed doi:10.1080/026404100419856

Mason, B., \& Cossor, J. (2000). What we can learn from competition analysis at 1999 pan Pacific Swimming Championships. In proceedings of XVIII Symposium on Biomechanics in Sports, Hong Kong, 75-82.

Marinho, D.A., Reis, V.M., Alves, F.B., Vilas-Boas, J.P., Machado, L., Silva, J., \& Rouboa, A.I. (2009). Hydrodynamic drag during gliding in swimming. Journal of Applied Biomechanics, 25, 253-257. PubMed

Miller, M.K., Allen, D., \& Pein, R. (2002). A kinematic and kinetic comparison of the grab and the track starts in swimming. Biomechanics and medicine in Swimming IX, University of Saint-Etienne, France, 231-234.

Naemi, R., Easson, W.J., \& Sanders, R.H. (2010). Hydrodynamic glide efficiency in swimming. Journal of Science and Medicine in Sport, 13, 444-451. PubMed doi:10.1016/j.jsams.2009.04.009

Psycharakis, S.G., \& Sanders, R.H. (2009). Validity of the use of a fixed point for intracycle velocity calculation in swimming. Journal of Science and Medicine in Sport, 12, 262-265. PubMed doi:10.1016/j.jsams.2007.11.008

Rouboa, A., Silva, A., Leal, L., Rocha, J., \& Alves, F. (2006). The effect of swimmer's hand/forearm acceleration on propulsive forces using computational fluid dynamics. Journal of Biomechanics, 39, 1239-1248. PubMed doi:10.1016/j. jbiomech.2005.03.012

Taylor, G.K., Nudds, R.L., \& Thomas, A.L. (2003). Flying and swimming animals cruise at a Strouhal number tuned for high power efficiency. Nature, 425, 707-711. PubMed

Vilas-Boas, J.P., Cruz, M.J., Sousa, F., Conceiçao, F., Fernandes, R., \& Carvalho, J. (2003). Biomechanical analysis of ventral swimming starts: comparison of the grab start with two track start techniques. Biomechanics and medicine in Swimming IX, University of Saint-Etienne, France, 249-252.

von Loebbecke, A., Mittal, R., Fish, F., \& Mark, R. (2009). A comparaison of kinematics of the dolphin kick in humans and cetaceans. Human Movement Science, 28, 99-112. PubMed doi:10.1016/j.humov.2008.07.005

Welcher, R.L., Hinrichs, R.N., \& Georges, T.R. (2008). Front or rear weighted track start or grab start: which is the best for female swimmers? Sports Biomechanics, 7, 100-113. PubMed doi:10.1080/14763140701683247

Winter, D.A. (1990). Biomechanics and motor control of human movement. (2nd ed.). New York: A. Wiley-Interscience Publication. 
